\title{
Ketotifen treatment of active colitis in patients with 5-aminosalicylate intolerance
}

\author{
John K Marshall MD FRCPC ${ }^{1}$, E Jan Irvine MD MSc FRCPC ${ }^{2}$
}

JK Marshall, EJ Irvine. Ketotifen treatment of active colitis in patients with 5-aminosalicylate intolerance. Can J Gastroenterol 1998;12(4):273-275. Mast cell stabilizers are commonly used in the treatment of asthma and allergic disorders. Although the role of mucosal mast cells in the pathogenesis of inflammatory bowel disease remains uncertain, mast cell stabilizers have been shown in animal models to attenuate the severity of experimental colitis. The authors' experience with ketotifen in three patients one each with Crohn's disease, ulcerative colitis and collagenous colitis - who had demonstrated allergy to, or intolerance of, 5aminosalicylic acid is reported.

Key Words: Aminosalicylate allergy, Collagenous colitis, Crohn's disease, Ketotifen, Mast cells, Ulcerative colitis

\section{Traitement au kétotifène d'une colite évolutive en présence d'intolérance au 5-aminosalicylate}

RÉSUMÉ : Les stabilisateurs des mastocytes sont couramment utilisés dans le traitement de l'asthme et des troubles allergiques. Bien que le rôle des mastocytes de la muqueuse soit méconnu dans la pathogenèse de la maladie intestinale inflammatoire, les stabilisateurs des mastocytes ont été jugés aptes à atténuer la gravité de la colite. Les auteurs font ici état de leur expérience avec le kétotifène chez trois patients atteints respectivement de maladie de Crohn, de colite ulcéreuse et de colite collagénique qui s'étaient révélés allergiques ou intolérants au 5-aminosalicylate.
$\mathrm{M}$ ucosal mast cells have been implicated in the pathogenesis of a number of gastrointestinal disorders, including Helicobacter pylori-associated peptic ulcer and ethanol-induced gastritis $(1,2)$. However, the role of mast cells in the pathogenesis of inflammatory disease of the colon remains controversial. While inconsistent changes in mucosal mast cell numbers have been observed in patients with inflammatory bowel disease $(3,4)$, mast cells derived from segments of active colitis have demonstrated an enhanced release of chemical mediators when stimulated to degranulate in vitro (5).

Pretreatment with mast cell stabilizers has been found to attenuate the development of experimental colitis in a number of animal models $(6,7)$. We report our experience with the administration of ketotifen, a potent mast cell stabilizer, to three patients with symptomatic colitis (one patient each with Crohn's disease, ulcerative colitis and collagenous colitis) who were allergic to, or intolerant of, 5-aminosalicylic acid (5-ASA).

\section{CASE PRESENTATION}

Case 1: A 60-year-old woman with a 24-year history of ulcerative pancolitis was evaluated in 1997 in an out-patient gastroenterology clinic for an acute flare-up of her disease. She had no other significant medical illnesses, but was allergic to penicillin and had undergone a remote tubal ligation. She had been maintained on oral sulfasalazine since 1977 with intermittent courses of oral corticosteroids for flare-ups,

This paper was a winning entry in the 'Consultations in Gastroenterology' Case Study Competition that was initiated and funded with the generous sponsorship of Astra Canada and is endorsed by the Canadian Association of Gastroenterology

${ }^{1}$ Clinical Scholar; ${ }^{2}$ Associate Professor, Division of Gastroenterology, Department of Medicine, McMaster University, Hamilton, Ontario

Correspondence: Dr John K Marshall, Division of Gastroenterology (4W8), McMaster University Medical Centre, 1200 Main Street West, Hamilton, Ontario L8N 325. Telephone 905-521-2100 ext 6402, fax 905-521-4958, e-mail marshll@fhs.mcmaster.ca 
which initially occurred every seven to eight years, but had become more frequent since 1995. In 1996, she experienced a refractory episode of diarrhea and abdominal pain, which resolved within $48 \mathrm{~h}$ of discontinuing sulfasalazine. A clinical diagnosis of 5-ASA intolerance was made when successive courses of sulfasalazine and mesalamine induced symptoms of diarrhea and abdominal pain, which also resolved within $48 \mathrm{~h}$ of drug withdrawal.

In February 1997, while on no medical therapy, the patient presented again with increased stool frequency and moderate lower abdominal cramping. Flexible sigmoidoscopy to $45 \mathrm{~cm}$ from the anal verge revealed a diffusely granular mucosa with micro-ulceration, loss of vascular pattern and purulent exudate. Mucosal biopsies revealed marked architectural distortion with deep plasma cells but no eosinophils, and a peripheral blood count showed no eosinophilia. A tapering course of prednisone was initiated with gradual improvement in her symptoms. However, repeated attempts over the following four months to reduce the dose below $15 \mathrm{mg} /$ day resulted in symptom recurrence. In June 1997, oral ketotifen was initiated at a dose of $1 \mathrm{mg}$ bid for one week and then increased to $2 \mathrm{mg}$ bid. Within three weeks the patient's bowel habit had normalized. Ketotifen was returned to $1 \mathrm{mg}$ bid, and the dose of prednisone was gradually reduced.

After two months on ketotifen, the patient remained in clinical remission despite reduction of her prednisone dose to $7.5 \mathrm{mg} /$ day. A flexible sigmoidoscopy to $60 \mathrm{~cm}$ showed improvement, with granular and friable mucosa, but no visible ulceration. After five months of ketotifen, prednisone was withdrawn, without clinical relapse.

Case 2: A 51-year-old female presented with an acute episode of diarrhea in 1991. Medical history included an allergy to penicillin and an episode of eosinophilic pneumonia in 1990, which had responded to oral corticosteroids. Colonoscopy revealed diffuse patchy erythema distal to the splenic flexure, with histological features of Crohn's colitis. There was no peripheral eosinophilia at the time and no excess of eosinophils in the colonic biopsy specimens. A diagnosis of 5-ASA allergy was made in 1991 when separate courses of 5 ASA suppositories and oral sulfasalazine were both associated with recurrence of eosinophilic pneumonia, requiring systemic corticosteroids. From October 1991 to January 1992, recurrent episodes of diarrhea were controlled with oral cholestyramine, a rectal corticosteroid foam and occasional opioid antidiarrheal agents.

In June 1992, the patient presented with an exacerbation of diarrhea while on no medical therapy but refused treatment with corticosteroids. Ketotifen was then introduced at $1 \mathrm{mg}$ bid and continued until September 1994. During that period she had only one symptomatic episode; it lasted six weeks and resolved with a short course of tapering corticosteroids. Since 1994, she developed a perianal fistula and suffered one flare-up of colitis requiring systemic corticosteroids in 1996. A colonoscopy at that time confirmed the diagnosis of Crohn's colitis, with no excess of eosinophils noted in mucosal biopsies.
Case 3: A 72-year-old female was followed in the out-patient gastroenterology clinic after a colonoscopy performed in 1990 to investigate her complaints of chronic diarrhea revealed the histological features of collagenous colitis. In 1991 she was prescribed mesalamine, but developed a fever and morbilliform skin rash, both of which resolved on drug withdrawal. A clinical diagnosis of allergy to 5-ASA was made.

In 1992 the patient developed a flare-up of her disease, with increased stool frequency and looser stool consistency. A trial of oral metronidazole (500 mg tid) produced no benefit, but her symptoms resolved while on a tapering course of oral corticosteroids. However, within five weeks of discontinuing prednisone the symptoms recurred, and a second tapering course of systemic corticosteroids was started in June 1992. In an attempt to reduce her steroid requirement, a sixmonth course of oral ketotifen ( $1 \mathrm{mg}$ bid) was initiated.

The patient remained well while on ketotifen. However, within two weeks of discontinuing ketotifen (in December 1992), she again observed an increase in stool frequency, which improved when the ketotifen was reintroduced. In May 1993, another course of corticosteroids was required and tapered gradually over four months. Ketotifen was finally discontinued at the patient's request in January 1994. She has since remained well and has required no further medical therapy.

\section{DISCUSSION}

This uncontrolled case series is the first reported use of oral mast cell stabilizers in patients with inflammatory disorders of the colon who were unable to tolerate 5-ASA derivatives. Case 1, who experienced steroid-dependent ulcerative colitis, was able to discontinue corticosteroids following the introduction of ketotifen. Case 2 was maintained on ketotifen for over two years, with only one flare-up of Crohn's colitis. Case 3, whose collagenous colitis remained in clinical remission while on ketotifen, appeared to relapse when ketotifen was withdrawn and improved when it was reintroduced. In no patient was any adverse effect of ketotifen therapy identified.

Ketotifen is a benzocycloheptathiophene derivative administered as a prophylactic agent in the management of bronchial asthma and allergic disorders. Although widely promoted as an inhibitor of mast cell degranulation, its true mode of action in asthma remains obscure and may include direct histamine antagonism, impaired release of inflammatory mediators by basophils, inhibition of activated eosinophils and suppression of $\mathrm{T}$ cell recruitment (8).

The known actions of ketotifen in colonic mucosa are also diverse. Ketotifen has been shown in vitro to reduce the accumulation of mucosal prostaglandin $\mathrm{E}_{2}$, leukotriene $\mathrm{B}_{4}$ and leukotriene $\mathrm{C}_{4}$ by $33 \%$ to $60 \%$ (9). Ketotifen has also been reported to alter the expression of inducible nitric oxide synthase, an important regulator of colonic inflammation, in colonic mucosal explants (10). Furthermore, a noncholinergic, nonhistaminergic myocontractile effect has been observed when isolated segments of rodent intestine are exposed to ketotifen (11). Doxantrazole, another 'mast 
cell stabilizer', has been reported to block 2,4,6-trinitrobenzene sulphonic acid-induced changes in the smooth muscle adrenoreceptors of guinea-pig intestine (12).

Ketotifen has been used successfully to treat a number of allergic disorders, including eosinophilic gastroenteritis, recurrent idiopathic anaphylaxis and chronic urticaria (13). It is of interest that two of our patients professed an allergy to penicillin, and that one had suffered a prior episode of eosinophilic pneumonia. Although the colonic biopsies were not specifically assessed for mast cell numbers or products of mast cell degranulation, none of our patients showed evidence of peripheral or mucosal eosinophilia when ketotifen was initiated, and none had other systemic manifestations of allergy. It is unclear, however, whether their symptomatic improvement was a result of an anti-inflammatory effect of ketotifen or of treatment of an unrecognized concomitant allergic disorder.

Each of our patients demonstrated intolerance to 5-ASA, which prompted our search for alternative therapeutic agents. Case 1 developed reversible diarrhea requiring drug withdrawal, a relatively common adverse event acknowledged in

\section{REFERENCES}

1. Nakajima S, Krishnan B, Ota H, et al. Mast cell involvement in gastritis with or without Helicobacter pylori infection. Gastroenterology 1997;113:746-54.

2. Karmeli F, Eliakim R, Okon E, Rachmilewitz D. Gastric mucosal damage by ethanol is mediated by substance $\mathrm{P}$ and prevented by ketotifen, a mast cell stabilizer. Gastroenterology 1991;100:1206-16.

3. Araki Y, Kakegawa T, Stadil F. Mast cells and histamine release in Crohn's disease. Kurume Med J 1993;40:93-9.

4. Deren JJ, Bai C, Sohn M, et al. Accumulation of mast cells and proteinases in the bowel wall in Crohn's disease but not ulcerative colitis. Gastroenterology 1996;110:A893. (Abst)

5. Fox CC, Lazenby AJ, Moore WC, Yardley JH, Bayless TM, Lichenstein LM. Enhancement of human intestinal mast cell mediator release in active ulcerative colitis. Gastroenterology 1990;99:119-24.

6. Eliakim R, Karmeli F, Okon E, Rachmilewitz D. Ketotifen ameliorates capsaicin-augmented acetic acid-induced colitis. Dig Dis Sci 1995;40:503-9.

7. Pothoulakis C, Karmeli F, Kelly CP, et al. Ketotifen inhibits Clostridium difficile toxin A induced enteritis in rat ileum. Gastroenterology 1993;105:701-7.

8. Hoshino M, Nakamura Y, Shin Z, Fukushima Y. Effects of ketotifen the literature. Reversible pulmonary eosinophilia, as observed in Case 2, is an increasingly recognized complication of 5-ASA therapy (14). Case 3 appeared to develop a hypersensitivity to mesalamine, characterized by a skin rash and fever that resolved upon drug withdrawal. While hypersensitivity reactions are more often associated with sulfasalazine, they can also occur following the administration of 5-ASA derivatives (15). A trial of ketotifen, with its antiallergic effects, may be particularly appropriate in colitic patients who, similar to our patients, develop adverse reactions to conventional drugs.

The benefit our patients appeared to derive from treatment with the mast cell stabilizer ketotifen provides the first evidence of a new class of therapeutic agents for patients with symptomatic colitis and 5-ASA intolerance or allergy. Although these results are clearly anecdotal, they highlight the potential role of mast cells and their mediators in the pathogenesis and progression of colonic inflammation. Further research is thus warranted to define better the mode of action of ketotifen, and to evaluate more rigorously its efficacy in patients with active inflammatory bowel disease.

on symptoms and on bronchial mucosa in patients with atopic asthma. Allergy 1997;52:814-20.

9. Eliakim R, Karmeli F, Chorev M, Okon E, Rachmilewitz D. Effect of drugs on colonic eicosanoid accumulation in active ulcerative colitis. Scand J Gastroenterol 1992;27:968-72.

10. Heyman SN, Karmeli F, Brezis M, Rachmilewitz D. The effect of ketotifen on nitric oxide synthase activity. Br J Pharmacol 1997;120:1545-51.

11. Abu-Dalu R, Zhang J, Hanani M. The actions of ketotifen on intestinal smooth muscles. Eur J Pharmacol 1996;309:189-93.

12. Martinolle JP, Garcia-Villar R, More J, Bueno L. Evidence for mast cell, leukotriene and nitric oxide involvement in the regulation of the adrenoreceptor number of inflamed small intestine in guinea pigs. Neurogastroenterol Motil 1995;7:187-95.

13. Patterson R, Fitzsimons EJ, Choy AC, Harris KE. Malignant and corticosteroid-dependent idiopathic anaphylaxis: successful responses to ketotifen. Ann Allergy Asthma Immunol 1997;79:138-44.

14. Bitton A, Peppercorn MA, Hanrahan JP, Upton MP. Mesalazineinduced lung toxicity. Am J Gastroenterol 1996;91:1039-40.

15. Hautekeete ML, Bourgeois N, Potvin P. Hypersensitivity with hepatotoxicity to mesalazine after hypersensitivity to sulfasalazine. Gastroenterology 1992;103:1925-7. 


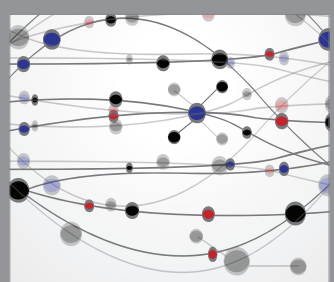

The Scientific World Journal
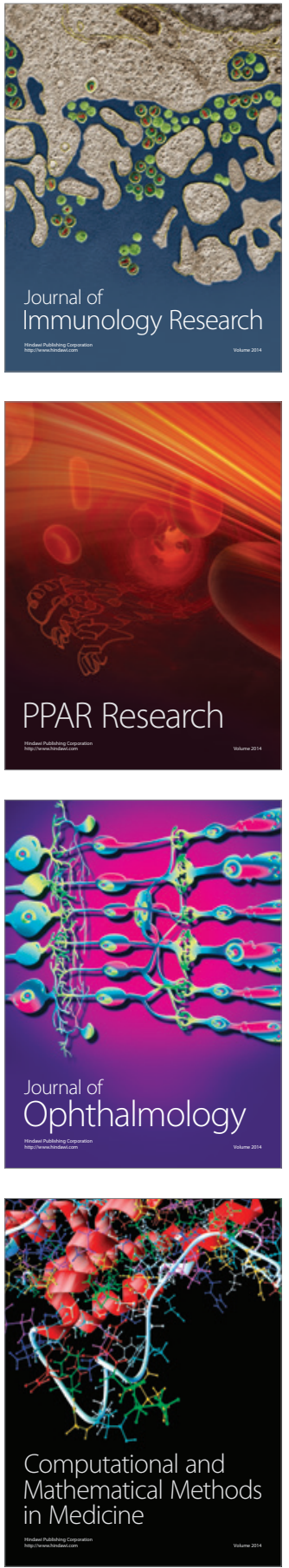

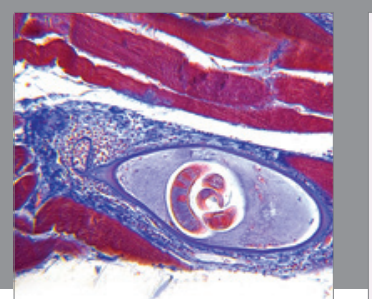

Gastroenterology Research and Practice

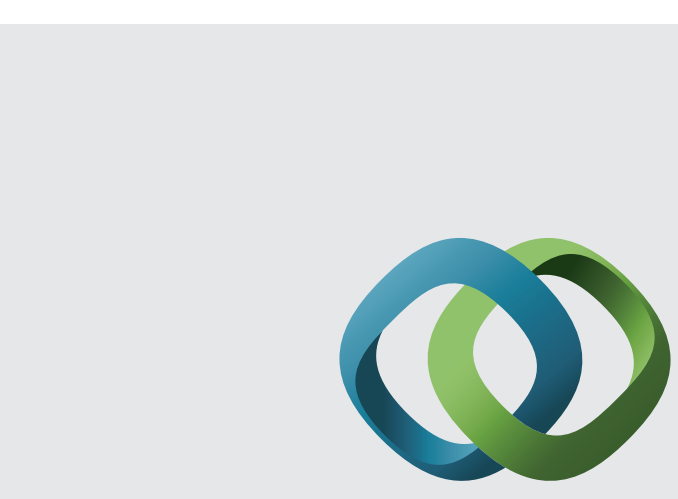

\section{Hindawi}

Submit your manuscripts at

http://www.hindawi.com
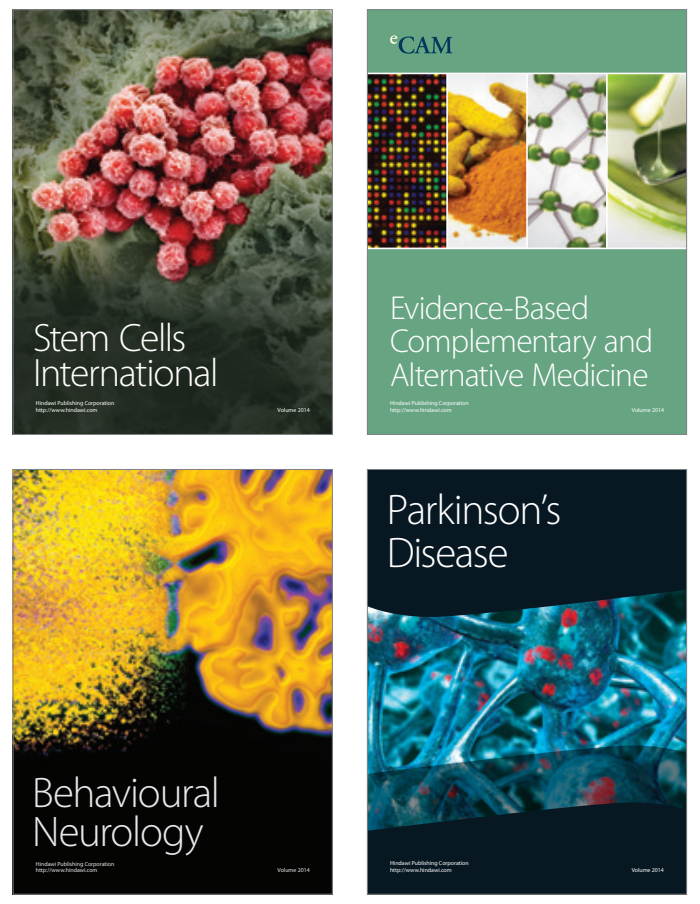
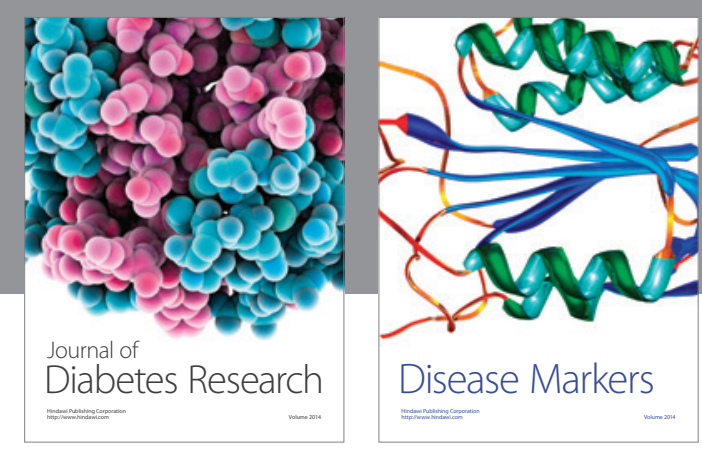

Disease Markers
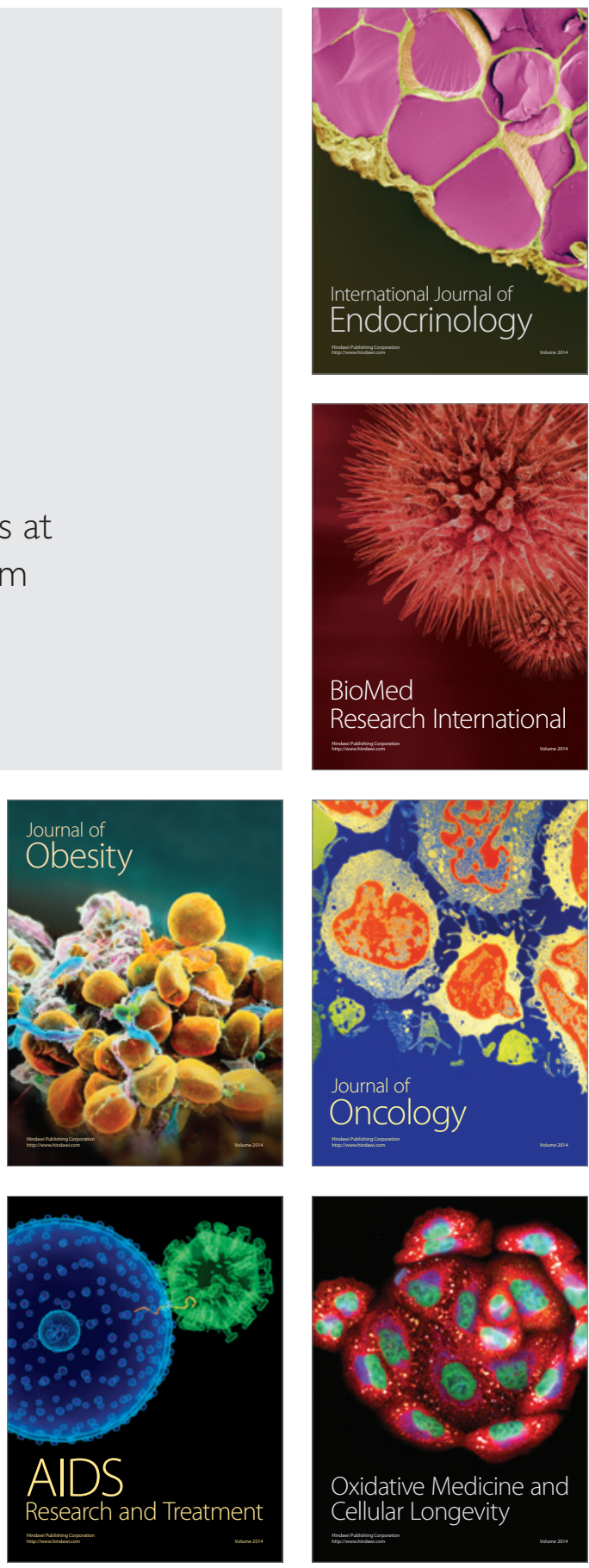